\title{
3 Research Suare \\ Digital Image Analysis of Spices and Condiments for Plant Taxonomic Studies
}

Haider lqbal Khan ( $\boldsymbol{\sim}$ khan@bmrau.edu.bd)

Bangabandhu Sheikh Mujibur Rahman Agricultural University https://orcid.org/0000-0001-9486-793X MIRA RANI DAS

ATI: Agricultural Training Institute

MA BASET MIA

Bangabandhu Sheikh Mujibur Rahman Agricultural University

Research article

Keywords: Image, digital herbarium, specimen, virtual

Posted Date: October 11th, 2021

DOI: https://doi.org/10.21203/rs.3.rs-944723/v1

License: (1) This work is licensed under a Creative Commons Attribution 4.0 International License.

Read Full License 


\section{Abstract}

To address the contemporary demand of the world in the 21 st century with the development of virtual technology, and to make the smart way of action with more efficiency, the department of Crop Botany, Bangabandhu Sheikh Mujibur Rahman Agricultural University (BSMRAU) have taken a step to launch a web-based computerized version of Digital Herbarium and Herbarium Museum of crop plants. This digital herbarium holds a large body of collections of images of special crops such as spices and condiments for improving academic and research capability which can be accessed anytime from anywhere in the world. Images can easily mirror and elucidate the characters that can be described theoretically. Photographic specimens can provide an important complement to herbarium collections by providing teaching and identify resources that are easily accessible to the community with digital herbarium. Digital image also guarantees instant access and increased user interaction as multiple people can work on a single model simultaneously and easily access information on descriptive details, published work, microscopic preparations, and nomenclature. The launched Digital Herbarium intends to make maximum use of primary research material to connect the research community and general public, including school children, and take care of public interest and enthusiasm for teaching spices and condiments.

\section{Introduction}

The oriental and occidental trade of the world is prominently influenced by spices and condiments. Diversified choice of people around the world necessitated a wide range of spices. Among the wide range, the most important spices and condiments are ginger, turmeric, cinnamon, clove, saffron, coriander, dill, fennel, pepper, black pepper, cumin, chili, vanilla, star anise, mace, mustard, cardamom, fenugreek, nutmeg, basil etc. They are being used in preparing many kinds of cuisine, sweets and value add as well (Dubey, 2017).

Spices have been playing a very crucial role as flavouring agents, preservatives and medicines for centuries. Over the past few decades, researchers have explored their health benefits significantly, as most spices are well-known to possess properties related to reducing the probability of developing chronic diseases (Vázquez-Fresno et al., 2019). Due to the presence of aroma, the essential oil spices are esteemed, therefore plant product used as a condiment or for flavouring food (Gadegbeku et al., 2014; Agize 2014). Combination of clove, black pepper, cinnamon and cardamom is used mostly in special meat curries and rice preparations (Ribeiro-Santos et al., 2017). They are also used in preparing many kinds of cookery and sweets, and some spices like black pepper, ginger, long pepper, clove, peppermint, ajowan, fenugreek are used in traditional and folk medicine (Opara and Chohan, 2014). Therefore, it's important to identify the spices for their traditional and proper use and application (Dubey, 2017).

At present the information technologies are impressively accelerating scientific research with simple, easy and flexible approach of accessing data, compiled from all the world including herbarium collections (Sousa-Baena et al., 2014). Multiple applications of digitized herbarium have been developed since the 1990s. Some provide tools for entering specimen records into databases and publishing them on the 
internet. The number of databases is continually increasing (Kislov et al., 2017; Seregin and Stepanova, 2020).

This change in scope explanation toward a presentation of information through electronic revenue has created a demand for high-quality images (Kalafi et al., 2016; Vilar et al., 2015). Students and academicians have come to look forward to instant access for getting information. Portable electronic devices such as handheld video players, video-enabled $\mathrm{mp} 3$ players, cellular phones capable of delivering images, and notebook computers have become more sophisticated and more widely available at the present as well as storing and delivering information cost has reduced (Soltis, 2017). These conveniences are great opportunities for education and research (Barbedo, 2013). The digital herbarium is an effective web application of detail information regarding plants which provides an ease to manage well with lots of plants electronically in a pleasant manner and having a user-friendly interface with amazing photos and details such as plant taxonomy, plant general morphological appraisal along with other botanic information (Corney et. al., 2012). Images itself reflect and illustrate the characters that described theoretically (Besnard et al., 2018). These photographic specimens can provide as important supplements to herbarium collections by providing teaching and identification resources that are easily accessible to the public (Beaman and Cellinese, 2012). Digital Image is very important for the learn of plant taxonomy, the study of geographic distributions, and the stabilizing of nomenclature that provides material for teaching such as botany, taxonomy, field botany, plant communities, ethnobotany, agriculture, dendrology, forestry (Meineke et al.,2018; Seregin and Stepanova, 2020). Digital Image also ensures instant access and increased user interaction as numerous persons can work on the same specimen instantaneously and provide convenient access to information on descriptive details, published work, microscopic preparations, and nomenclature through hyperlinks (Henning et al., 2018; Hendrick et al., 2019).

With the scientific advancement over time, and to make the action more user responsive, accessible and efficient in use, the hardworking academicians of the department of Crop Botany, Bangabandhu Sheikh Mujibur Rahaman Agricultural University (BSMRAU) came forwarded to launch an online web version of Digital Herbarium and Herbarium Museum of crop plants. This Digital herbarium hold numerous images of special crops such as spices and condiment for improving academic and research capability which can be accessed anytime from anywhere in the world. The intent is to connect the research community and the general public including school children to make greater use of primary research material and to take care of the public interest and excitement in the learning of spices and condiments. Concerning to image analysis of spices and condiments the current project has been undertaken to convert the morphological characteristics and taxonomically important features of the spices and condiments by using digital images of herbarium into digital information for plant identification and for inspiring the public with the aims and methods of botanical science to get back the information in the network environment, ensure the development of lesson plans and developed research by using primary research materials from the herbarium and to establish cooperation between the different institutions and the development of an interactive BSMRAU with a Web-based portal. 


\section{Materials And Method}

Although the idea of digital herbarium is a relatively new domain which is becoming very popular over the last 30 year (Seregin and Stepanova, 2020). For the development of digital herbarium in relation to spice and condiments, meticulous and collaborated efforts were made in cooperation of the project personnel, different universities and research organizations. It is a computerized program where image and plant parameters of different plant species are accessible on a compiled database, and unknown plant species could be identified from that database. This technique will enhance the knowledge on the image analysis of plants, and will give a boost to the application of information technology in plant sciences. This work included tasks from sample collection, taxonomic classification, photo shoot, literature preparation and uploading the whole formatted data to the website. The layout was sketched considering the content and the user group, and it was prepared to provide interactive experience between the users and the database contents.

Then website was designed and developed considering the layout. The design and layout of web app of digital herbarium has been completed and ready for inspection (Figure 2). Information regarding crop sciences has been published with necessary formatting, image editing and upload. For effective implementation of the study materials, the project also involves the development of an e-learning portal that will engage students from inside and outside the campus. Different interfaces were connected to continue smooth flow of information for the development of website and e-learning system, and established linking algorithm. Plant digital image information of spice and condiments was designed by combining with Microsoft Visual Basic 6.0 Enterprise Edition database management system and Structure Query Language.

\section{Higher Education Quality Enhancement Project (HEQEP)}

The department of Crop Botany, Bangabandhu Sheikh Mujibur Rahaman Agricultural University (BSMRAU) completed the subproject entitled "Establishment of Digital Herbarium and Herbarium Museum for improving Academic and Research Capability in Crop Botany" under the project of Higher Education Quality Enhancement Project (HEQEP) funded by World Bank. Establishment of digital herbarium and herbal museum for improving academic and research capability in crop botany with the financial help from window 2 of academic innovation fund (AIF) of higher education quality enhancement project (HEQEP) under University Grants Commission of Bangladesh (UGCB) is being implemented by Department of Crop Botany, BSMRAU. Image and database of crop plants comprising field were digitized and developed a virtual herbarium, software and e-learning processes comprehensively. The virtual herbarium is linked with the websites of BSMRAU.

Although sets of digital images can serve some of the same functions as physical specimens, it is available towards more people at a time. Large plant image collections have been assembled by absorbing smaller image collections as a result of coordinated contributions from many individuals. Because the images come from multiple sources, their quality and the data associated with them is not uniform. Ornamental and photogenic species are over-represented. Hence species are not 
that charismatic or are difficult to identify, are under or unrepresented. Often photographs of some features, such as bark or twigs, are not included. In other cases, several features may be combined in a single image. Image quality varies, and images may not be available at high resolution. The systematic collection of standardized digital images will address most of these problems. Standardized, systematic representation of features will allow comparison among taxa, and presentation of the variation among and within individuals. The capability to easily observe this variation allows users to recognize the plants in a visually natural way (Kirchoff, 2008). The system realized electronic management and retrieval of local plant information. The presence of many detailed images from the same individual also allows verification of the taxonomic identity, resulting in the production of a reliable collection of images. Occurrence data associated with these image sets adds to the distribution database for the species. Sets of digital images would complement, but not replace, traditional physical specimens in herbaria (Dillen et al., 2019). We should consider collecting images systematically as we do with physical specimens. Systematic collection would facilitate using the images in ways that take advantage of our remarkable abilities to process visual information.

Digital image have important roles in assisting in plant identification, and teaching taxon recognition (Cope et al., 2012). Set of digital image can supplement herbarium collection. To maintain appropriate manner in time image collection are more effective. Image of spices and condiments have been collected over a long period of time and recorded. This record provides historical and ecologically important data, but because it provides information useful in the identification of unusual specimens. A single image from time to time represents all of the features of a plant. If enough features are photographed, a set of images can adequately represent the gross morphology of a species. As aids of identification, sets of images are probably superior to herbarium specimens. Color and habit are better represented in images as is the living form of the plant. A set of photographs including pictures of the flower, leaves, stem and the whole plant is much more likely to allow learners to make correct identifications (Seregin, 2020). With regard to their use in learning, images may also be superior to herbarium specimens. Images depict the three-dimensional orientation of features more accurately than do pressed specimens. They represent features that are difficult or impossible to preserve in specimens, they also more accurately represent color. Although a single image cannot capture all of this variation, a set of images can. As records of occurrence, digital images can be as good as physical specimens, assuming that they capture sufficient information to allow unambiguous identification. If any features of the plant that are not photographed at the time of collection cannot be recorded at a later time, the photographer is able and willing to collect a physical specimen from the same plant, and if a reference to that physical specimen is included in the metadata associated with the image. Thinking of image sets as specimens can influence the way that we collect and organize images, which may increase their value as tools for education and research.

\section{Results And Discussion}

The key works of image analysis of spices and condiments included family, genus, morphological characteristics, and habitat and so on. 


\section{Imaging of live plants}

High quality of images require on the move toward to presentation of information through electronic way. Digital cameras is the most effective way and affordable to produce these images. As a result, the number of images available to students and faculty is much higher than at any time in the past. As the internet set in motion to develop, photographers quickly realized that slide images and specimens could be shared more widely when they were digitized and made electronically available. Digital images over represent the most photogenic species, and present few features of each plant. These photographic specimens can serve as important supplements to herbarium collections by providing teaching and identification resources that are easily accessible to the public.

\section{Spice and condiment of BSMRAU digital herbarium}

There are various features of a plant's collection and appearance that are used by expert botanists in plant morphological research.

Hottest chili (Capsicum chinense Jack.) ( http://dhcrop.bsmrau.net/hottest-chili/) : Image has taken in the flowering stage as well as fruit set in twig another one is ripe fruit, and processed chili in bottle.

Canary grass (Phalaris canariensis L.) (http://dhcrop.bsmrau.net/canary-grass/): There are one picture in field, grass with inflorescence/cob/panicle.

Celery (Apium graveoliens L.)(http://dhcrop.bsmrau.net/celery/): Image of whole plant in field.

Bay leaf ( Cinnamomum tamala (Buch.-Ham.) T.Nees \& Eberm.)( http://dhcrop.bsmrau.net/indiancassia/?doing_wp_cron ): Image has taken whole plant in field, another one twig and one more leave.

Rrosemary (Rosmarinus officinalis L.)( http://dhcrop.bsmrau.net/3710-2/): There are whole plant in field and an additional one whole plant with flower in field. Rosemary oil is used for purposes of fragrant bodily. perfumes or to emit an aroma into a room. It is also burnt as incense, and used in shampoos and cleaning products.

Star anise (Illicium verum Hook.)( http://dhcrop.bsmrau.net/star-anise-2/) : Image has in use fruits in plant, another image flower in plant and a further one carpel and seed.

Laurel (Laurus nobilis L.)( http://dhcrop.bsmrau.net/laurel/?doing_wp_cron): Twig with leaves image has here.

Basil ( Ocimum basilicum L.)( http://dhcrop.bsmrau.net/basil/): There are image of twig with flowering , Stem Anatomy, Leaf Anatomy, Inflorescence

Olive (Olea europea) (http://dhcrop.bsmrau.net/olive/?doing_wp_cron): Here is whole plant in field and another one flowering and one mature fruit in plant. 
Fenugreek(Trigonella foenum-graecum L.)( http://dhcrop.bsmrau.net/3454-2/): There are image of one is whole plant, whole plant in field and methi itself(fruit/seed).

Camellia (Camellia spp.)(http://dhcrop.bsmrau.net/camellia/?doing_wp_cron): There are image of whole plant with flower.

Clove (Syzygium aromaticum (L.) Merr. \& L.M.Perry)(http://dhcrop.bsmrau.net/clove/): There are one is heading, colve itself, whole plant, flowering and inflorescence and harvested clove.

Pepper (Piper nigrum)( http://dhcrop.bsmrau.net/pepper/): There are image of whole plant, leaf and fruit in inflorescence.

Lemon grass (Cymbopogon citratus (DC.) Stapf) ( http://dhcrop.bsmrau.net/lemon-grass/): Image has taken of lemmon grass in field.

Panbilash (Clausena heptaphylla) (http://dhcrop.bsmrau.net/panbilash/): Here is leaf in plant.

Turmeric(http://dhcrop.bsmrau.net/3016-2/): There are image of plant in field and some are flowering stage, whole plant and rhizome.

Ginger ( Curcuma longa L.) ( http://dhcrop.bsmrau.net/zinger/?doing_wp_cron): There are image of rhizome, close view of rhizome, plant with rhizome and adventitious root system, picture of different part of plant and whole plant and flower of ginger plant.

Aloo Bokhara (Prunus bokharensis) (http://dhcrop.bsmrau.net/aloo-bukhara/): Image has taken of whole plant, fruit with plant, stem anatomy,leaf anatomy, close view of fruit with plant, close view of fruit with plant and close view of fruit with plant. The tree is of medium hardiness.

Curry patta (Murraya koenigii (L.) Spreng) (http://dhcrop.bsmrau.net/curry-patta/): There are image of whole plant, fruit with twig in plant.

Fennel (Foeniculum vulgare Mill.) ( http://dhcrop.bsmrau.net/fennel/?doing_wp_cron): Here is image of whole plant in field,flowering in field, and harvested curry fruit/seed.

Cardamom (Elettaria cardamomum (L.) Maton) (http://dhcrop.bsmrau.net/cardamon/): (A): whole plant in field,(B): real stem of plant underground of rhizome, (C): infloroscense, (D): capsule.

Black cumin (Nigella sativa L.) (http://dhcrop.bsmrau.net/black-cumin/?doing_wp_cron): (A): whole plant in field,(B): close view of flower,(C): harvested blackcumin of BU kalajira-1 variety,(D): flowering stage,(E) : close view of capsule,(F): burst capsule.

Saffron(Crocus cartwrightianu)( http://dhcrop.bsmrau.net/saffron/): (A): whole plant in field with flower.

Chili (Capsicum spp.) (http://dhcrop.bsmrau.net/2564-2/) : Video are present, (A): twig of plant with flower, (B): fruiting stage of whole plant, (C): whole plant with root in laboratory,(D): cross section of chilli 
stem, (E): BARI variety of sweet pepper, (E): BARI variety of sweet pepper.

Vanilla (Vanilla planifolia Jacks. ex Andrews)( http://dhcrop.bsmrau.net/vanilla/): (A): one is plant with flower.

Garlic (Allium sativum L.) (http://dhcrop.bsmrau.net/garlic/): (A): plant in field, (B): mulching in field, (C): umbel inflorescence,(D): (E): umbel inflorescence.

Coriander (Coriandrum sativum L.)( http://dhcrop.bsmrau.net/coriander/): (A): whole plant in field with flowering stage, (B): close view of flower, after harvested coriander.

Cinnamon (Cinnamomum verum J.Presl) (http://dhcrop.bsmrau.net/2046-2/): whole plant in field, $3^{\text {rd }}$ stem, $4^{\text {th }}$ bark and $5^{\text {th }}$ whole plant (close view), another photo is twig.

Cumin (Cuminum cyminum L.) (http://dhcrop.bsmrau.net/2034-2/): (A): whole plant in field with flowering stage, (B): another harvested cumin.

Indian olive ( Elaeocarpus serratus L.) (http://dhcrop.bsmrau.net/indian-olive/): (A): whole plant, (B): close view of inflorescence, (C): stem of plant,(D): root anatomy, (E): stem anatomy, (F): leaf anatomy.

Linseed (Linum usitatissimum L.) ( http://dhcrop.bsmrau.net/1351-2/): Video has present, (A): whole plant of linseed in field, (B): close view of whole plant, (C): (D) close view of flower. (E): linseed after harvested.

Black mustard/true mustard ( Brassica nigra (L.) Koch) (http://dhcrop.bsmrau.net/black-mustard/): (A): whole plant, black mustard.

Our new algorithm locates leaves, stem and features of spices and condiments are most useful and performance against a manually analyzed subset of the images. The algorithm achieves an accuracy of features are sufficient to identify different species of different spices (Kislov et al., 2017; Groom et al., 2017). The global climate is changing rapidly, changes in plant flowering times of warming temperatures gives us a way to look at the impacts of climate change and allows us to predict further changes in coming decades. (Panchen et al., 2012). Phenological information included in digital herbarium archives can produce annual phenological estimates and it may be utilized due to their longer duration and ability to discriminate among the various components of the plant community, hold imperative potential for use in future research to supplement the deficiencies of other data sources as well as address a wide array of important issues in ecology (Park, 2012). The shapes of plant leaves are of great importance to plant biologists and botanists, as they can help in distinguishing plant species and measure their health (Laga et al., 2013). Digital pictures of leaves were enhanced, segmented, and a set of features were extracted from the image. (Joaci de M. Sá Junior et al., 2011, Easlon and Bloom, 2014, Wijesingha and Marikar,2012). 
Advances in online resources and electronic publication provide the sciences with tools to revolutionize education and research. (Brach and Boufford, 2011). Image identification of plant requires the domain knowledge in the botanist field (Hussein et al., 2011). Image processing used for objective evaluation of quality parameters which is rapid, economical with great advantages in its objectiveness, efficiency and reliability (Dressler et al., 2017). The taxonomic classification of spices and condiments has usually been done by simple morphological observation and visual comparison, although the use of biometric indices has often proved to be a powerful approach in the taxonomic studies of the genus. Using image analysis techniques, (Orrù et al., 2013). Image analysis reassesses the taxonomic position of some neglected or doubtful taxa (Bacchetta et al., 2011). Identification keys require the observation of one or more morphological characters of an organism at each step of the process. While modern digital keys can overcome several constraints of classical paper-printed keys, their performance is not error-free (Carranza-Rozas et al., 2017). Moreover, identification cannot be always achieved when a specimen lacks some morphological features (Bruni et al., 2012). The characteristics of plant leaves image features are used to plant leaves classification and recognition (Du et al., 2013). Recognition of plant images is one of the research topics of computer vision. Object shape is more informative than its appearance properties such as texture and color vary between object instances more than the shape and focuses mainly on image enhancement, morphological feature such as area convexity (Bhardwaj et al., 2013; CarranzaRozas et al., 2017). In recognition of different plant species through their leaf images is investigated by decision-making algorithm. The algorithm is employed to investigate inside the feature search space in order to obtain the best discriminant features for the recognition of individual species (Dressler et al., 2017).

In order to establish a feature search space, a set of feasible characteristics such as shape, morphology, texture and color are extracted from plant species (Ghasab et al.,2015). Using a computer-aided imaging analysis has been capable to identify of the seed morphometric variation as well as detect differences in seed morphology, both within and among populations. Morpho-colorimetric analysis clearly identified seeds from different populations and discriminated (Santo et al., 2015). Generally, cultivar identification is done on the basis of distinctive traits, such as shape, size, colour of the testa and ornamentations. Therefore, it is important, from both technical and economical points of view, to have a quick, reliable, repeatable, and nondestructive method to be able to identify and classify seeds objectively (Seregin and Stepanova, 2020). In order to promote computerised image analysis as a tool to aid visual inspection in the discrimination of different seeds, this technique was applied to analyze and identify seeds of varieties (Soltis, 2017). The assessment of some seed aspects such as colour, size and shape is important in grading system as well as to characterize accessions of core collections (Iva e al., 2013). Morphocolorimetric quantitative variables describing seed size, shape, colour and texture were analyzed using image analysis techniques (Bianco et al., 2015). Human perception of plant leaf and flower colour can influence species management. Colour and colour contrast may influence the detectability of invasive or rare species during surveys. For measuring plant leaf and flower colour traits using images taken with digital cameras. The analysis of digital images taken with digital cameras is a practicable method for identifying in the field or lab (Kendal et al., 2013). Plant species classification using leaf samples is a 
challenging and important problem to solve. This motivates a separate processing of three feature types: shape, texture, and margin; combined using a probabilistic framework (Mallah et al., 2013). Colour, size and shape of seeds are very important in the grading system for many crops. Image analysis system for spices and condiments seeds was able to highlight differences among varieties and different stability of variety (Smykalova et al., 2011). The steps of image analysis done in some image processing focusing on agriculture application and also the details analysis of parallel and distributed image processing (Nasir et al., 2012).

Adopting features and orientations allows alongside comparison of images and the creation of standard displays for the identification of closely related species. Since the set of images from a given individual is intended to be a photographic specimen, the image set must contain enough images to allow the plant to be definitely identified at the species level (Walter et al., 2015). To make this possible, as complete a set of primary features as is practical should be taken from the same individual plant. The locality of each individual should also be recorded.

\section{Recommendations}

Images photographed can be used for a variety of purposes, including taxon identification, comparison of similar taxa while learning taxon recognition, and presentation in print publications or posters. Such uses require high quality images present the subject in a method that does not detract from the feature being presented. If the educational promise of digital plant images is to be fulfilled, many high quality images must be collected and made available. To accomplish these goals and this level of quality, the following recommendations are suggested:

1. Photographic standards should be developed for taxa other than plants.

2. The discussion of standards for photographing live plants needs to become part of the broader discussion of standards for sharing digital data. This discussion is ongoing for the sharing of metadata with different organization such as Bangladesh Agricultural Research Institute (BARI), Bangladesh Rice Research Institute (BRRI), Bangladesh Institute of Nuclear Agriculture (BINA), Bangladesh Jute Research Institute (BJRI), Bangladesh Sugar Crop Research Institute (BSRI), Bangladesh Tea Research Institute (BTRI) etc.

3. Digital image specimen collections should in due lessons take account of multiple individuals of each species. This would bless users to consider the range of variation among individuals in a specified area, and across the species' geographic range.

4. Progression should be developed to let for appearance of distance scales beside the images, without disrupting the images themselves. Because the images should be fitting for presentation in learning environments and print applications, people in the actual image is not recommended. 5 . The images necessitate being permanently archived consent to resource developers to locate and access the 
originals. This can be accomplished by acclimatized biodiversity collections software to create suitable databases, or archiving the images in an on-line image repository.

6. A minimum image resolution of 6.0 megapixels will discuss images suitable for most print applications, and for enlargement to allow assessment of details here in the image.

7. The use of flash for seal images bring into being maximum depth of field, reduces blurring from camera motion, and minimizes distracting background. Flash photography allows for rapid, high quality photography even under the poor lighting conditions common in forests, and on cloudy days.

\section{Conclusion And Future Of Live-plant Images}

The contemporary speedy advance of powerful electronic, software, and network tools and the installation of determined projects reveal the huge potential of the web to deliver image enhanced education. The use of more and more widespread image based resources such as handheld video players and the wireless internet provide an unparallel opportunity to produce image based content and deliver it to a large addressees. However, this opportunity will be unrealized without high quality images required in order prepare the content. A large collection of publicly available digital live-plant images need to the hard work of finding, identifying, and photographing plants in the field. This reality has two important implications that is unlikely labor-intensive work will be redone in the future if it is strong-minded that some features or quality is lacking in the existing images. Secondly, locating and identifying the plants themselves is a challenge collective with the compilation of physical specimens. This challenge can only be meet successfully with the cooperation of herbaria and the professionals associated with them. Identification of specimens can best be skillful at the time of imaging if the photographer is an expert, or if the photographer goes together with an expert into the field. Many of the goals and challenges concerned in creating new image-based plant educational resources are collective with those of traditional herbaria. Consequently these challenges can be best met through collaboration with the existing networks of herbaria.

\section{Declarations}

\section{Funding}

We acknowledge the support of a Higher Education Quality Enhancement Project (HEQEP) [Grant Numbers CP 3084] funded by World Bank and implemented by University Grant Commission of Bangladesh as the main funding source of the project.

\section{Contributions}

HI Khan and MA Baset Mia planned the study. Mira Rani Das and HI Khan executed the project and data collection under the guidance of MA Baset Mia. The virtual library is managed and maintained by $\mathrm{HI}$ 
Khan and MA Baset Mia. HI Khan, Mira Rani Das and MA Baset Mia drafted, revised, and approved the final manuscript.

\section{Acknowledgement}

The Authors acknowledge the financial support of World Bank through the HEQEP project implemented by the University Grant Commission (UGC) of Bangladesh. Special thanks for all the members of the dept. of Crop Botany of Bangabandhu Sheikh Mujibur Rahman Agricultural University, for cordial support to execute the programmme successfully.

\section{Data and materials}

I Haider lqbal Khan declare the availability of all the data and link of the work to be published in Evolution: Education and Outreach and presenting myself as the corresponding author

I understand that the text and any pictures or videos published in the article will be freely available on the internet and may be seen by the general public. The pictures, videos and text may also appear on other websites or in print, may be translated into other languages or used for commercial purposes.

I have been offered the opportunity to read the manuscript.

\section{Consent form}

I Haider lqbal Khan give my consent about my work to be published in Evolution: Education and Outreach and presenting myself as the corresponding author

I understand that the information will be published without my name attached, but that full anonymity cannot be guaranteed.

I understand that the text and any pictures or videos published in the article will be freely available on the internet and may be seen by the general public. The pictures, videos and text may also appear on other websites or in print, may be translated into other languages or used for commercial purposes.

I have been offered the opportunity to read the manuscript.

With this letter I declare the Ethics approval and consent to participate with the paper.

Signing this consent form does not remove my rights to privacy.

\section{Competing interests}

The authors declare that they have no competing interests.

\section{References}


1. Agize M.. Ethnobotany of spice and condiment plants and the associated indigenous knowledge on management, utilization and conservation of them in and around home gardens in Loma and Gena Bosa Districts (Weredas) of Dawuro Zone, Southern Ethiopia. International Journal of Agriculture Innovations and Research. 2014; 4(3):426-442, ISSN (Online) 2319-1473

2. Bacchetta G, García PE, Grillo O, Mascia F, Venora G. Seed image analysis provides evidence of taxonomical differentiation within the Lavatera triloba aggregate (Malvaceae). Flora - Morphology, Distribution, Functional Ecology of Plants. 2011; 206(5): 468-472. https://doi.org/10.1016/j.flora.2011.01.006

3. Arnal Barbedo JG. Digital image processing techniques for detecting, quantifying and classifying plant diseases. ; SpringerPlus 2. 2013; 660. https://doi.org/10.1186/2193-1801-2-660

4. Beaman RS, Cellinese N. Mass Digitization of Scientific Collections: New Opportunities to Transform the Use of Biological Specimens and Underwrite Biodiversity Science. ZooKeys. 2012; 209: 7-17. https://doi.org/10.3897/zookeys.209.3313

5. Besnard G, Myriam G, Sébastien L, Muller S, Rouhan G, Sukhorukov AP, Vanderpoorten A, Jabbour F. Herbarium-based science in the twenty-first century. Botany Letters. 2018; 165(3-4): 323-327. https://doi.org/10.1080/23818107.2018.1482783

6. Bhardwaj A, Kaur M, Kumar A. Recognition of plants by Leaf Image using Moment Invariant and Texture Analysis. International Journal of Innovation and Applied Studies. 2013; 3(1):237-248.

7. Bianco ML, Ferrer-Gallego P, Grillo O, Laguna E, Venora G, Bacchetta G. Seed image analysis provides evidence of taxonomic differentiation within the Medicago L. sect. Dendrotelis (Fabaceae). Journal Systematics and Biodiversity. 2015;13(5):484-495. http://dx.doi.org/10.1080/14772000.2015.1046968

8. Brach AR, Boufford DE. "Why Are We Still Producing Paper Floras?". Annals of the Missouri Botanical Garden. 2011; 98(3):297-300. http://dx.doi.org/10.3417/2010035

9. Bruni I, De Mattia F, Martellos S, Galimberti A, Savadori P, Casiraghi M, Nimis PL, Labra M. DNA Barcoding as an Effective Tool in Improving a Digital Plant Identification System: A Case Study for the Area of Mt. Valerio, Trieste (NE Italy). PLoS ONE. 2012; 7(9): e43256. https://doi.org/10.1371/journal.pone.0043256

10. Carranza-Rojas J, Goeau H, Bonnet P, Mata-Montero E, Joly A. Going deeper in the automated identification of Herbarium specimens. BMC Evolutionary Biology. 2017; 17:181. https://doi.org/10.1186/s12862-017-1014-z

11. Cope JS, Corney D, Clark JY, Remagnino P, Wilkin P. Plant species identification using digital morphometrics: A review. Expert Systems with Applications. 2012; 39(8): 7562-7573. https://doi.org/10.1016/j.eswa.2012.01.073

12. Corney DPA, Tang HL, Clark JY, Hu Y, Jin J. Automating Digital Leaf Measurement: The Tooth, the Whole Tooth, and Nothing but the Tooth. PLoS ONE. 2012; 7(8):e42112. https://doi.org/10.1371/journal.pone.0042112 
13. Dillen M, Groom Q, Chagnoux S, Güntsch A, Hardisty A, Haston E, Livermore L, Runnel V, Schulman L, Willemse L, Wu Z, Phillips S. A benchmark dataset of herbarium specimen images with label data. Biodiversity Data Journal. 2019; 7: e31817. https://doi.org/10.3897/BDJ.7.e31817

14. Dressler S, Gregor T, Hellwig F, Korsch H, Wesche K, Wesenberg J, Ritz C. Comprehensive and reliable: a new online portal of critical plant taxa in Germany. Plant Systematics and Evolution. 2017; 303:1109-1113. https://doi.org/10.1007/s00606-017-1419-6

15. Du J, Zhai C, Wang Q. Recognition of plant leaf image based on fractal dimension features. Neurocomputing. 2013; 116:150-156. https://doi.org/10.1016/j.neucom.2012.03.028

16. Dubey S. Indian Spices and their Medicinal Value. Indian Journal of Pharmaceutical Education and Research. 2017; 51(3):330-332. DOI: 10.5530/ijper.51.3s.41

17. Easlon HM, Bloom AJ. Easy Leaf Area: Automated Digital Image Analysis for Rapid and Accurate Measurement of Leaf Area. Applications in Plant Sciences. 2014; 2(7):1400033. https://doi.org/10.3732/apps.1400033

18. Gadegbeku C, Tuffour MF, Katsekpor P, Atsu B. Herbs, spices, seasonings and condiments used by food vendors in Madina, Accra. Caribian journal of Science and Technology. 2014; 2:589-602.

19. Ghasab MAJ, Khamis S, Mohammad F, Fariman HJ. Feature decision-making ant colony optimization system for an automated recognition of plant species. Expert Systems with Applications. 2015; 42(5): 2361-2370. https://doi.org/10.1016/j.eswa.2014.11.011

20. Groom Q, Hyam R, Güntsch A. Stable identifiers for collection specimens. Nature. 2017; 546: 33. https://doi.org/10.1038/546033d

21. Hedrick B, Heberling M, Meineke E, Turner K, Grassa C, Park D, Kennedy J, Clarke J, Cook J, Blackburn D, Edwards S, Davis C. Digitization and the future of natural history collections. Peer J Preprints. 2019; 7:e27859v1. https://doi.org/10.7287/peerj.preprints.27859v1

22. Henning T, Plitzner P, Güntsch A, Berendsohn WG, Müller A, Kilian N . "Building Compatible and Dynamic Character Matrices Current and Future Use of Specimen-Based Character Data". Botany Letters. 2018; 165 (3-4). https://doi.org/10.1080/23818107.2018.1452791

23. Hussein AN, Mashohor S, Saripan MI. "A texture-based approach for content based image retrieval system for plant leaves images". IEEE 7th International Colloquium on Signal Processing and its Applications. 2011: 11-14. https://doi.org/10.1109/CSPA.2011.5759833

24. Iva S, Oscar G, Marie B, Martin P, Gianfranco V. Phenotypic evaluation of flax seeds by image analysis. Industrial Crops and Products. 2013; 47: 232-238. https://doi.org/10.1016/j.indcrop.2013.03.001

25. Sá Junior JJ de M, Backes AR, Rossatto DR, Kolb RM, Bruno OM. Measuring and analyzing color and texture information in anatomical leaf cross sections: an approach using computer vision to aid plant species identification. Botany. 2011; 89(7): 467-479. https://doi.org/10.1139/b11-038

26. Kalafi EY, Tan WB, Town C, Dhillon SK. Automated identification of Monogeneans using digital image processing and Knearest neighbour approaches. In 15th International Conference On Bioinformatics 
(InCoB 2016): Bioinformatics. BMC Bioinformatics. 2016.17:511. https://doi.org/10.1186/s12859016-1376-Z

27. Kendal D, Hauser CE, Garrard GE, Jellinek S, Giljohann KM, Moore JL. Quantifying Plant Colour and Colour Difference as Perceived by Humans Using Digital Images. PLoS ONE. 2013; 8(8): e72296. https://doi.org/10.1371/journal.pone.0072296

28. Kirchhoff AJ. Digital preservation: challenges and implementation. Learned Publishing. 2008; 21(4):285-294. https://doi.org/10.1087/095315108X356716

29. Kislov DE, Bakalin VA, Pimenova EA, Verkholat VP, Krestov PV. An electronic management system for a digital herbarium: development and future prospects. Botanica Pacifica. 2017;6 (2):59-68. doi: $10.17581 /$ bp.2017.06207

30. Laga H, Kurtek S, Srivastava A, Golzarian M, Miklavcic SJ. "A Riemannian Elastic Metric for ShapeBased Plant Leaf Classification". In 2012 International Conference on Digital Image Computing Techniques and Applications (DICTA). 2013.pp: 1-7. DOI: 10.1109/DICTA.2012.6411702

31. Mallah C, Cope J, Orwell J. Plant Leaf Classification using Probabilistic Integration of Shape, Texture and Margin Features. Acta Press. From Proceeding (797) Computer Graphics and Imaging / 798: Signal Processing, Pattern Recognition and Applications - 2013. DOI: 10.2316/P.2013.798-098

32. Meineke EK, Davis CC, Davies TJ. . "The Unrealized Potential of Herbaria for Global Change Biology". Ecological Monographs. 2018; 88(4):505-525. https://doi.org/10.1002/ecm.1307

33. Nasir AFA, Rahman MNA, Mamat AR. A Study of Image Processing in Agriculture Application under High Performance Computing Environment. International Journal of Computer Science and Telecommunications. 2012; 3(8):16-24

34. Opara El, Chohan M. Culinary Herbs and Spices: Their Bioactive Properties, the Contribution of Polyphenols and the Challenges in Deducing Their True Health Benefits International Journal of Molecular Science. 2014; 15(10): 19183-19202. https://doi.org/10.3390/ijms151019183

35. Orrù $M$, Grillo $O$, Lovicu G, Venora G, BacchettaG. Morphological characterisation of Vitis vinifera L. seeds by image analysis and comparison with archaeological remains. Vegetation History and Archaeobotany. 2013; 22(3): 231-242. https://doi.org/10.1007/s00334-012-0362-2

36. Panchen ZA, Primack RB, Anisko T, Lyons RE. Herbarium specimens, photographs, and field observations show philadelphia area plants are responding To climate change.. American Journal of Botany. 2012; 99(4): 751-756. https://doi.org/10.3732/ajb.1100198

37. Park IW. Digital herbarium archives as a spatially extensive, taxonomically discriminate phenological record; a comparison to MODIS satellite imagery. International Journal of Biometeorology. 2012; 56 (6): 1179-1182. https://doi.org/10.1007/s00484-012-0521-2

38. Ribeiro-Santos R, M Andrade, Madella D, Martinazzo AP, Moura LAG, de Melo NR, Sanches-Silva A. Revisiting an ancient spice with medicinal purposes: Cinnamon. Trends in Food Science \& Technology. 2017; 62: 154-169. https://doi.org/10.1016/j.tifs.2017.02.011

39. Santo A, Mattana E, Grillo O, Bacchetta G. Morpho-colorimetric analysis and seed germination of Brassica insularis Moris (Brassicaceae) populations. Plant Biology. 2015; 17(2): 335-343. 
https://doi.org/10.1111/plb.12236

40. Seregin AP. Moscow Digital Herbarium: a consortium since 2019. Taxon. 2020; 69 (2):417-419. https://doi.org/10.1002/tax.12228

41. Seregin AP, Stepanova NY. MHA Herbarium: Eastern European collections of vascular plants. Biodiversity Data Journal. 2020; 8:e57512. https://doi.org/10.3897/BDJ.8.e57512

42. Smykalova I, Grillo O, Bjelkova M, HybI M, Venora G. Morpho-colorimetric traits of Pisum seeds measured by an image analysis system. Seed Science and Technology. 2011; 39(3): 612-626. https://doi.org/10.15258/sst.2011.39.3.08

43. Soltis PS. Digitization of herbaria enables novel research. American Journal of Botany. 2017; 104 (9): 1281 - 1284. https://doi.org/10.3732/ajb.1700281

44. Sousa-Baena MS, LCGarcia, Peterson AT. Completeness of digital accessible knowledge of the plants of Brazil and priorities for survey and inventory. Diversity and distributions. 2014; 20(4): 369-381. https://doi.org/10.1111/ddi.12136

45. Vázquez-Fresno R, Rosana ARR, Sajed T, Onookome-Okome T, Wishart NA, Wishart DS. Herbs and Spices- Biomarkers of Intake Based on Human Intervention Studies - A Systematic Review. Genes and Nutrition. 2019; 14: 18. https://doi.org/10.1186/s12263-019-0636-8

46. Vilar WTS, Aranha RM, Medeiros EP, Pontes MJC. Classification of Individual Castor Seeds Using Digital Imaging and Multivariate Analysis. Journal of the Brazilian Chemical Society. 2015; 26 (1):102-109. http://dx.doi.org/10.5935/0103-5053.20140221

47. Walter A, Liebisch F, Hund A. Plant phenotyping: from bean weighing to image analysis. Plant Methods. 2015; 11:14. https://doi.org/10.1186/s13007-015-0056-8

48. Wijesingha D, Marikar F. Automatic Detection System for the Identification of Plants Using Herbarium Specimen Images. Tropical Agricultural Research. 2012; 23(1):42-50. http://doi.org/10.4038/tar.v23i1.4630

\section{Figures}




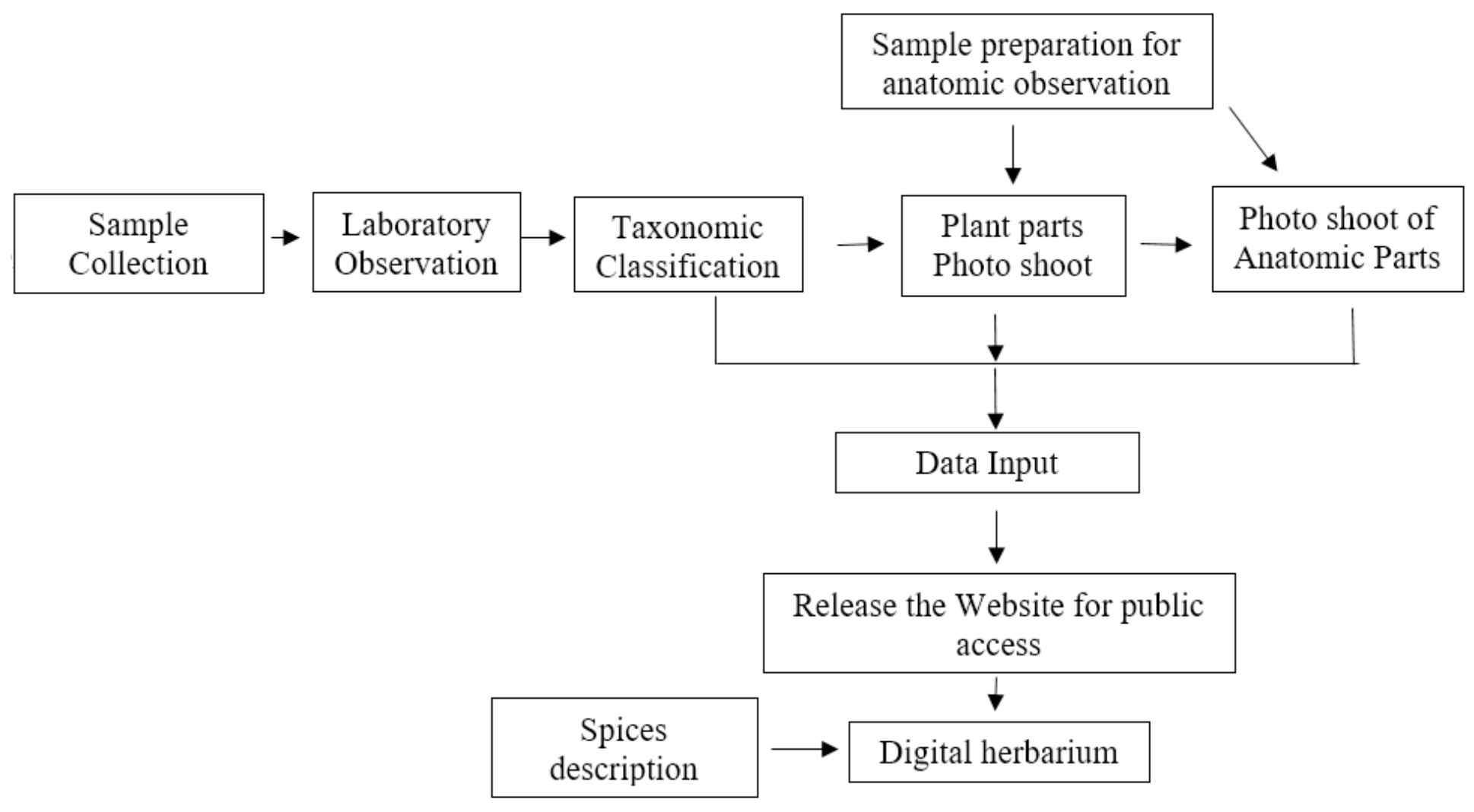

Figure 1

Sketch of the tasks involved for content preparation and layout of the web app of digital herbarium

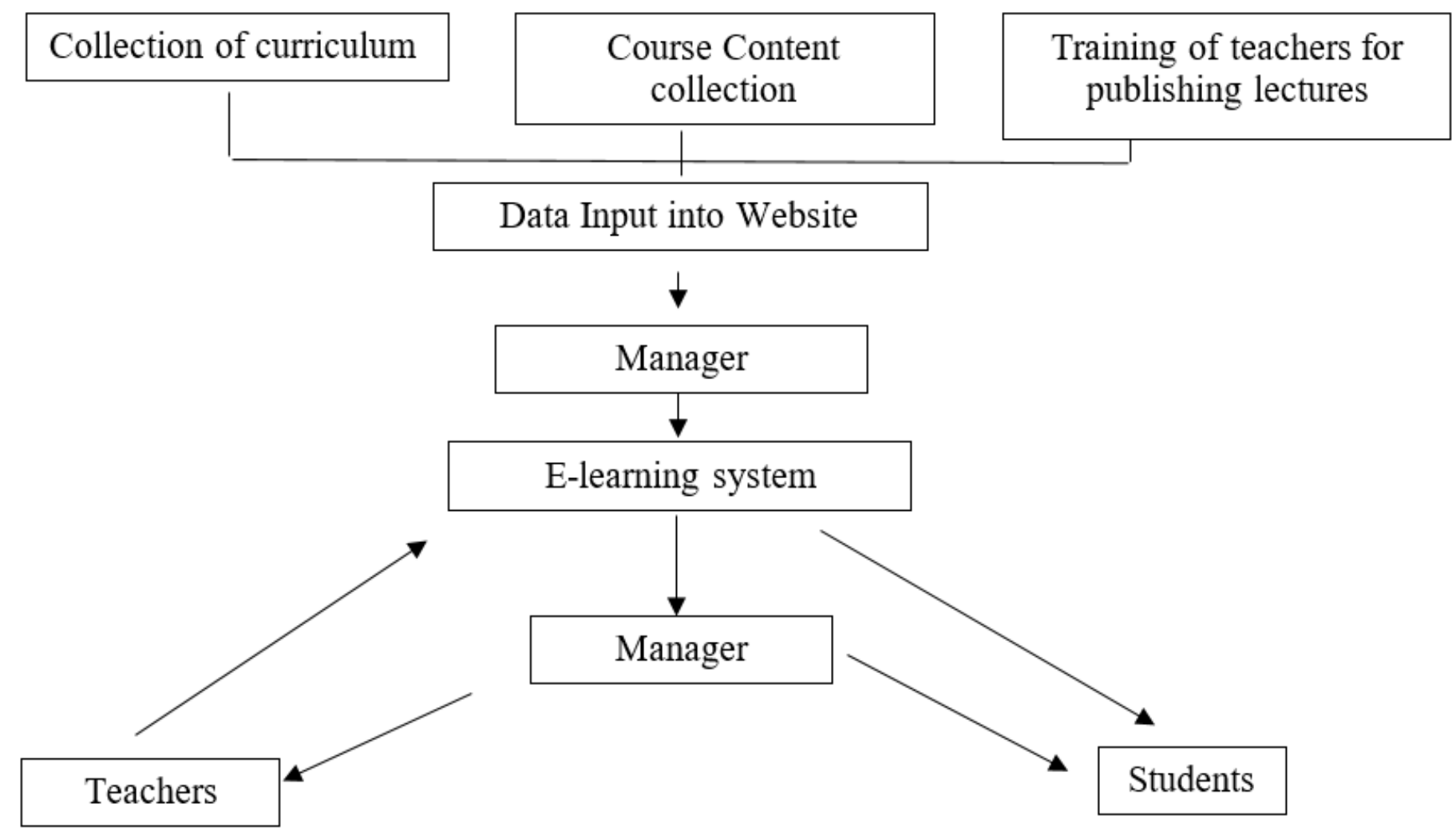


Figure 2

Algorithm model for the site and e-learning system development of web 